\title{
O EMPIRISMO JURÍDICO: A ESCOLA HISTÓRICA E OS OBSTÁCULOS EPISTEMOLÓGICOS À CIENTIFICIDADE DO DIREITO
}

\section{THE LEGAL EMPIRICISM: THE HISTORICAL SCHOOL AND OBSTACLES EPISTEMOLOGICAL TO SCIENCE OF LAW}

\author{
${ }^{1}$ Pedro Miron de Vasconcelos Dias Neto \\ ${ }^{2}$ Emmanuel Teófilo Furtado
}

\section{RESUMO}

O objetivo principal desta pesquisa acadêmica dirige-se ao estudo das premissas, dos fundamentos teórico-valorativos e dos eventuais óbices epistemológicos do empirismo jurídico à ciência jurídica, principalmente na perspectiva da realidade social do Direito. Por outro giro, reconhece-se a importância da Escola Histórica do Direito enquanto marco de transição do jusnaturalismo para o juspositivismo, bem como a promoção da valorização do produto histórico e espontâneo peculiar a cada povo. Utiliza como referencial teórico a doutrina de Karl Popper, assimilando dois problemas fundamentais que permeiam a teoria do conhecimento: (1) pode-se saber mais do que se sabe? e (2) quando uma ciência não é uma ciência? Com efeito, sob a análise empírico-jurídico-histórica, perquire-se: enunciados factuais que se baseiam sobretudo na experiência podem ser válidos universalmente? Desta forma, através de pesquisa bibliográfica, do método dialético e do exame crítico, pretende-se concatenar algumas possíveis reflexões sobre os assuntos ora propostos.

Palavras-chave: Empirismo jurídico, Escola histórica do direito, Epistemologia, Ciência do direito.

\begin{abstract}
The main objective of this academic research addresses the study of the assumptions, the theoretical and evaluative foundations and possible epistemological obstacles of legal empiricism to legal science, particularly in view of the social reality of law. On the other turning, it recognizes the importance of the historical school of law as a transitional framework of natural law theory for legal positivism, and to promote the appreciation of the peculiar historical and spontaneous product every people. It uses as a theoretical doctrine of Karl Popper, assimilating two fundamental problems that underlie the theory of knowledge: (1) one can know more than we know? and (2) when a science is not a science? Indeed, in the empirical-legal-historical analysis, it investigates: factual statements that are based mainly on experience can be universally valid? In this way, through bibliographic search, the dialectical method and critical examination, intend to concatenate some possible reflections on the issues.
\end{abstract}

Keywords: Legal empiricism, Historical school of law, Epistemology, Science of law.

\footnotetext{
${ }^{1}$ Doutorando em Direito na Universidade Federal do Ceará - UFC, Fortaleza - CE (Brasil). Procurador Federal da Advocacia-Geral da União no Estado do Ceará (Brasil). E-mail: pedromiron@ hotmail.com

${ }^{2}$ Doutor em Direito pela Universidade Federal de Pernambuco - UFPE, Recife - PE (Brasil). Professor da Universidade Federal do Ceará - UFC, Fortaleza - CE (Brasil). E-mail: emmanueltf@trt7.jus.br
} 


\section{INTRODUÇÃO}

O presente artigo científico tem como objetivo analisar as premissas e os fundamentos teóricos, práticos e valorativos do empirismo jurídico, notadamente da Escola Histórica, na perspectiva da realidade social do Direito. Neste ponto, perquire-se principalmente se o empirismo jurídico (através do corte escolhido, isto é, por intermédio da Escola Histórica) constitui obstáculo epistemológico à elaboração científica do Direito?

Nesta esteira, a pesquisa bibliográfica será a principal fonte de investigação através de pesquisa exploratória que vise a trazer maior familiaridade com os diversos aspectos teóricos e práticos que serão abordados no decorrer da pesquisa acadêmica. Neste ponto, o método adotado em relação aos dados bibliográficos será o dialético, que promove o confronto de argumentos contraditórios, o que garantirá o exame crítico da pesquisa.

Inicialmente, aborda-se a relação do direito natural com a ideia de contrato social, inclusive a posterior transmudação relacional da crença do direito divino no direito como produto humano, ou seja, como corolário da razão e da cultura. Tem-se, portanto, uma profunda hegemonia do homem enquanto ser central do universo.

Neste propício ambiente histórico-cultural antropocêntrico, entretanto, surge o Historicismo, refratário à ideia dos racionalistas que consideravam a humanidade de forma abstrata (e não de forma individualizada ou particularizada). Neste ponto, algumas características são analisadas: ideia de tragicidade (pessimismo antropológico); apego ao passado; força da tradição; dentre outros.

Por conseguinte, no âmbito do Historicismo, o comprometimento da pesquisa se dirige com a Escola Histórica do Direito. Neste ponto, tem-se o seu surgimento como marco deflagrador da passagem da filosofia jusnaturalista para a juspositivista. Ademais, realiza-se a abordagem da Escola Histórica enquanto vertente da corrente empirista jurídica, fincada no nascimento da ciência do Direito através da experiência e da realidade.

Com efeito, após a análise da importância da epistemologia ao estudo da ciência do Direito, utiliza-se como referencial teórico o pensamento de Karl Popper. Neste ponto, a investigação do Autor aponta dois problemas fundamentais que norteiam à teoria do conhecimento: o problema da indução e o problema da demarcação. 
Outrossim, indagam-se: enunciados factuais que se baseiam sobretudo na experiência - Escola Histórica do Direito - podem ser válidos universalmente? De outra forma, existem obstáculos epistemológicos à cientificidade do Direito sob a perspectiva do empirismo jurídico? Por outro giro, com fulcro no falsifacionismo de Popper, po de- se concluir que o conhecimento não se forma da indução pela experiência do real?

Assim, com o desenvolvimento do presente artigo, pretende-se responder ou tentar responder algumas destas perguntas ora elencadas. De fato, a intenção será apenas jogar algumas luzes à eterna discussão acerca da cientificidade do Direito. Neste ponto, o cotejo do empirismo jurídico à luz da epistemologia parece demonstrar alguns possíveis caminhos ao pesquisador.

\section{O DIREITO NATURAL E O CONTRATO SOCIAL}

Desde a antiguidade, as teorias acerca de um direito natural dos homens sempre permearam a mente dos pensadores e filósofos de sua época. Nesta perspectiva jusnaturalista, entretanto, no período de transição entre a idade média e a idade moderna, observou-se uma mudança de concepção.

$\mathrm{Na}$ idade média havia a crença na existência de um direito natural divino, inserido numa compreensão cosmológica de que as leis emanavam diretamente de Deus e aos homens cabia, tão somente, forjar um direito terreno que guardasse uma aproximação sempre tendente à identificação do direito mundano ao direito ideal divino.

$\mathrm{Na}$ idade moderna, por sua vez, houve uma verdadeira revolução copernicana no que diz respeito à alteração desse paradigma. Neste ponto, já não era de Deus que emanavam as leis naturais tendentes à concordância com um direito natural ideal, e, sim, produto da razão.

Ressalta-se, contudo, que essa mudança de paradigma não se deu de maneira linear e homogênea. Alguns autores do direito natural clássico, como Leibniz, ainda colocavam Deus como a fonte última do direito natural, entretanto, a laicização do estudo do direito se tratava de fenômeno indomável.

Assim, num momento onde os homens alongavam seus horizontes e as ciências delineavam a construção de um mundo novo, também foi dado ao direito um lugar pomposo no substrato da razão. Nesta medida, tal como podiam desenvolver teoremas 
matemáticos e geométricos, os homens também detinham a capacidade de desenhar sua própria versão de um direito ideal - não construído de uma apreciação metafísica - mas de algo que aos indivíduos parecia muito mais palpável e possível de ser alcançado: a ratio humana.

Inaugurada por Hugo Grócio, a nova concepção de direito natural se desprendeu de preceitos metafísicos distantes do mundo sensível e colocou na razão humana o princípio último de todas as coisas ${ }^{1}$. A razão humana participaria, então, da formação de um conjunto de normas consideradas ideais, isto é, que guardavam a noção do que o Direito deveria ser.

Com efeito, desse direito ideal não positivado, erigiam-se as noções que formariam o direito posto, ou seja, que sempre buscaria a devida aproximação com o direito natural. Assim coloca Hugo de Brito Machado Segundo², “o jusnaturalismo caracterizava-se pelo recurso à existência de normas não positivadas, as quais serviriam de modelo e dariam fundamento, quando observadas, ao direito positivo".

De outro giro, Arnaldo Vasconcelos ${ }^{3}$, com fulcro em Franz Wieacker, afirma que o Direito natural exerce a função de regra de crítica jurídica, atuando simultaneamente por duas vertentes: como método de conhecimento e como modelo de Direito positivo. O objetivo da norma de Direito natural, por sua vez, seria o da realização da justiça, tendo historicamente cumprido tal mister. Desta forma, considerando a justiça como valor, chegou-se a assimilar o Direito natural enquanto filosofia da justiça.

Por conseguinte, esse novo tipo de compreensão do direito construiu terreno para o nascimento de teorias que amoldariam a nova face do cenário político da idade moderna. A partir do momento em que se percebeu que do indivíduo emanariam as diretivas para a concretude do Estado e da sociedade, colocou-se o homem em posição de destaque - antropocentrismo - não sendo mais mero instrumento dos desígnios divinos.

Ficou evidente, então, que o homem moderno agora seria autor da própria história. As teorias contratuais, em suas diversas vertentes, mostraram isso. Seja num estado de natureza idílico (Rousseau) ou num estado de natureza bélico (Hobbes), seria o indivíduo, por intermédio do uso de sua razão, que agiria para a formação da sociedade.

Para os contratualistas poderem fazer essa construção teórica, entretanto, foi imperativo que previamente fosse alterada a visão de como o indivíduo se inseria na coletividade. Nada obstante, um contrato pressupunha autonomia de vontade entre as partes 
e, portanto, o indivíduo só seria capaz de figurar em tal acordo possuindo o domínio de sua razão.

A racionalidade importaria em uma condição diferente de participação do indivíduo na sociedade. Assim, enquanto na antiguidade grega, as figuras do homem e da polis convergiam para a formação do cidadão dotado de liberdade (um não existia sem o outro), na idade moderna, homem e Estado se colocavam em posições antagônicas.

Decerto, a extrapolação dessa concepção dualista entre indivíduo e Estado culminou do radicalismo vivido nas últimas fases do liberalismo, quando era defendido que o Estado seria um verdadeiro mal, tão-somente necessário para a manutenção das liberdades individuais 4 .

$\mathrm{Na}$ construção do Estado moderno, portanto, as teorias acerca do direito natural e do contrato social caminharam lado a lado, sendo necessárias para a criação do novo modelo de indivíduo. Neste ponto, um ser humano (indivíduo) que não estava mais entregue à sorte das vontades do soberano ou de Deus; capaz de perceber o seu papel na formação da sociedade, quer seja por via do contrato firmado perante o Estado, quer seja na formação racional das leis.

\section{O HISTORICISMO}

\subsection{CONSIDERAÇÕES GERAIS}

O Historicismo foi um movimento importante de ideias e pensamentos surgidos e desenvolvidos no século XIX. Apresentou-se em franca oposição às correntes acionalistas, quais sejam, devotas ao raciocínio puro, abstrato e ao método dedutivo, desprezando a observação dos fatos 5 .

Nesta perspectiva, verificam-se, pelo menos, três correntes diversas no Historicismo: o filosófico, de Schelling e Hegel; o político, dos teóricos da Restauração; e o Historicismo jurídico - também denominado de Escola histórica -, sobretudo dos juristas alemães ${ }^{6}$.

O Historicismo Filosófico, também denominado idealismo objetivo, foi tratado de forma genérica por Schelling, a quem correspondeu a idéia fundamental. Quanto a Hegel, coube o mérito de tê-lo desenvolvido e aperfeiçoado em um sistema rigoroso, qual seja, o 
idealismo absoluto em sentido objetivo, que negava dogmaticamente qualquer limite ao conhecimento, isto é, o próprio absoluto seria cognoscível ${ }^{7}$.

Já o Historicismo Político ${ }^{8}$, também denominado de Filosofia da Restauração, nasceu de circunstâncias e contingências particulares, isto é, de uma reação à teoria e à prática da Revolução Francesa. Desta forma, assumiu caráter predominantemente teocrático, na medida em que convalidou a autoridade da tradição com o dogma da investidura divina. Regressava-se, portanto, às formas próprias do pensamento medieval para subtrair os regimes políticos à crítica dos povos e dos filósofos ${ }^{9}$.

Desta forma, em sua manifestação de conotação política, o Historicismo estaria intrinsecamente ligado à Santa Aliança, que pretendia recuperar a imagem da monarquia perante o mundo. Neste ponto, execrava o pensamento racionalista, alertava que o presente não poderia romper com o passado (político) sem, contudo, provocar sérios riscos comprometedores a toda a vida do Estado e da sociedade ${ }^{10}$.

Adiante, o Historicismo Jurídico, que não tinha, a priori, nenhuma intenção filosófica ou política, vinculando-se à proposta eminentemente científica. No entanto, também surgiu pela reação contra a Revolução Francesa, considerando que as instituições políticas se baseiam na história e na tradição dos povos. Desta feita, seria grave erro mudá-las com a ajuda de raciocínios abstratos e de caráter universal, sendo por isso a crítica de Edmundo Burke (1729-1791) à Declaração dos direitos do homem e do cidadão, qualificando-a de digesto da anarquia ${ }^{11}$.

\subsection{CARACTERÍSTICAS DO HISTORICISMO}

De acordo com BOBBIO ${ }^{12}$, as características do Historicismo giravam em torno da maneira com que seus defensores compreendiam o homem, ou seja, no fato de o homem ser entendido a partir de sua singularidade, individualidade, distintamente dos racionalistas que consideravam a humanidade abstrata. Nesta perspectiva doutrinada pelo professor italiano, destacam-se os seguintes traços do movimento historicista:

(a) Variedade da história devido à variedade do próprio homem: indica que não existe “o Homem", com caracteres sempre iguais e imutáveis, conforme aduziam os jusnaturalistas, todavia há uma diversidade de homens que se distinguem em função de diversos fatores, a exemplo da raça e do período histórico em que vivem. Carreando essa 
conclusão para a esfera jurídica, tem-se que se não existe um homem único, modelo, de igual forma não se pode defender a existência de um direito único. $\mathrm{O}$ direito não é uma ideia da razão, mas, sim, um produto da história, variando no tempo e no espaço;

(b) $\underline{\mathrm{O} \text { sentido do irracional na história: }}$ traço diametralmente oposto à interpretação racionalista da história, segundo os iluministas. Para os historicistas, a história não é produto da razão, do cálculo cartesiano, mas decorre da não-razão, do elemento emotivo e passional do homem, do sentimento. Veja que esse traço aproxima o Historicismo do Romantismo, justamente porque exalta que a história se alimenta de algo misterioso, obscuro, existente na alma humana. Essa visão sob o prisma jurídico informa que o direito não é fruto de uma avaliação racional, porém nasce do sentimento de justiça gravado no coração do homem, por mais indecifrável que possa parecer tal sentimento. E essa sensação do justo e do injusto exprime-se por meio das formas jurídicas mais primitivas, populares, como é o caso do costume, que sempre estarão por baixo do direito artificial criado pelo Estado moderno;

(c) Ideia da tragicidade (pessimismo antropológico): enquanto o iluminista é manifestamente otimista, por acreditar ser possível o homem, com sua razão, alterar o estado das coisas e promover o desenvolvimento da sociedade, o historicista carrega a marca do pessimismo, a descrença no progresso humano, precisamente por vislumbrar a crueza da realidade e os vícios sociais. Para os historicistas, essas mudanças revolucionárias nada mais escondem do que os interesses dos poderosos de governar a massa humana, jogando com suas paixões, através da defesa de supostos "direitos do homem". Na seara do direito, essa incredulidade quanto à eficácia das reformas propostas pelos iluministas conforma-se com a conservação dos ordenamentos existentes e a desconfiança das novas instituições jurídicas que se pretendam impor à sociedade. Por isso, a Escola Histórica, vertente jurídica do Historicismo, opôs-se ferozmente ao projeto de codificação do direito germânico, julgando ser inviável ao povo alemão a cristalização do direito em um único documento legislativo. Não sem motivo, a codificação alemã tardou um século, se comparada com outros países europeus;

(d) Apego ao passado: ora, se os historicistas não creem no futuro da humanidade, a saída é depositar profunda admiração pelo passado, idealizando-o. Interessam-se pelas origens da civilização e pelas sociedades primitivas, contrariamente aos iluministas, que, declaradamente, zombam do passado, ao mesmo tempo em que enaltecem 
as "luzes" da Idade racionalista. O reflexo disso na esfera jurídica é que os historicistas procuraram redescobrir o direito romano, bem como reviver o antigo direito germânico;

(e) Força da tradição: defendem a permanência das instituições e costumes existentes na sociedade e formados a partir de lento e secular desenvolvimento histórico. É a noção de prescrição histórica: vale aquilo que é formado no curso do acontecer histórico, consagrado no tempo ${ }^{13}$. Os iluministas, ao revés, desprezavam a tradição e suspeitavam de tudo aquilo que era repetido mecanicamente, devendo o espírito inovador reformular as instituições e os costumes, por meio da razão. Essa característica do Historicismo, na Escola Histórica do Direito, vem representada pela defesa do costume como forma particular de produção jurídica, verdadeira expressão da tradição de um povo (nasce diretamente do povo e exprime o sentimento e o espírito do povo). Vale atentar que o Historicismo Jurídico subverte a clássica relação entre as duas fontes do direito, na medida em que oferta prevalência ao costume em sobreposição à própria lei.

Com efeito, após se debruçar sobre as características gerais do Historicismo, o viés desta pesquisa se dirige especificamente à Escola Histórica do Direito. Neste ponto, vislumbrar-se-á as perspectivas iniciais do seu surgimento, bem como as suas possíveis contribuições (e obstáculos) teóricos para a consolidação da ciência do Direito.

\section{DO SURGIMENTO DA ESCOLA HISTÓRICA DO DIREITO ÀS CRÍTICAS E CONTRADIÇÕES AO HISTORICISMO}

O Historicismo Jurídico emergiu, de fato, através do escrito de 1798 do alemão Gustavo Hugo, cujo título é tão sintomático quanto interessante: Tratado do direito natural como filosofia do direito positivo, significando que o direito natural não é mais concebido como um sistema normativo autossuficiente, mas, sim, como um conjunto de considerações filosóficas sobre o próprio direito positivo. Desta forma, conforme assinala BOBBIO, a obra de HUGO assinala a passagem da filosofia jusnaturalista para a juspositivista (lato sensu $)^{14}$.

Adiante, ainda de acordo com a lição de BOBBIO, para compreender o que é Historicismo não há nada melhor do que ler algumas páginas de Meinecke, contidas no Prefácio As Origens do Historicismo (trad. It., Sansoni, Florença, 1954), nas quais, entre 
outras, encontramos uma célebre definição do significado e da função do jusnaturalismo:

\begin{abstract}
Dizemos aqui brevemente o que é essencial[...]. O primeiro princípio do Historicismo consiste em substituir uma consideração generalizante e abstrata das forças histórico-humanas por uma consideração de seu caráter individual[...]. Acreditava-se que o homem com sua razão e suas dores, com suas virtudes e seus vícios tivesse permanecido em todos os tempos substancialmente o mesmo. Esta opinião contém, sim, um germe de verdade, mas não compreende as profundas transformações que a vida moral e espiritual do indivíduo e da comunidade sofre e assume, não obstante permaneça inalterada quanto às qualidades humanas fundamentais. A postura jusnaturalista do pensamento, predominante desde a antiguidade, inculcava a fé na imutabilidade da natureza humana, antes, da razão humana[...]. Esse jusnaturalismo[...] tem sido a estrela polar em meio a todas as tempestades da história e constituído para o homem pensante um ponto fixo na vida, tanto mais forte se sustentado pela fé na Revelação (Pref., pp. X-XI) (destaque nosso) ${ }^{15}$.
\end{abstract}

Assim, conforme se depreende acima, o que caracteriza o Historicismo é o fato dele considerar o homem na sua individualidade e em todas as variedades que tal individualidade comporta, opondo-se ao racionalismo que considera a humanidade $\operatorname{abstrata}^{16}$.

Com efeito, o maior expoente da Escola Histórica do Direito foi o alemão Frederico Carlos Savigny - autor de "a vocação de nosso Século para a Legislação e a Ciência do Direito (1814)" - sendo seguido por seu discípulo Jorge Frederico Puchta, autor de “o Direito Costumeiro". De outro giro, o Historicismo também está ligado ao romantismo literário do século passado 17 .

Já quanto aos antecessores mais diretos do pensamento historicista, geralmente apontados, são: Vico, Montesquieu e Burke, este já citado anteriormente. No entanto, alguns autores vislumbram traços historicistas nos últimos capítulos de “As Leis”, de Platão, ou, ainda, algumas ideias historicistas na obra do jurisconsulto romano Gaio, sendo estas posteriormente apresentadas e desenvolvidas por Savigny 18 .

Desta forma, enquanto que no jusnaturalismo, as reflexões sobre o Direito inclinaram-se para o abstrato e para o racional, com o surgimento da Escola Histórica as atenções convergiram para a experiência, para os fatos da sociedade e seus costumes19

Decerto, verifica-se que a Escola Histórica do Direito se constituiu como reação filosófica ao racionalismo, na medida em que a história possuiria um sentido irracional. Neste ponto, não seria possível, portanto, compartilhar-se do otimismo iluminista, que 
enxergava na razão uma força propulsora e transformadora do mundo, sendo capaz de sanear todos os males da humanidade.

Assim, a abordagem histórica do Direito foi verificada - não como mero produto racional - mas dantes um produto histórico e espontâneo peculiar a cada povo ${ }^{20}$. A Escola Histórica do Direito é, portanto, eminentemente anti-racionalista, opondo-se à filosofia iluminista através de uma dessacralização do direito natural, substituindo o abstrato e o universal pelo particular e pelo concreto 21 .

Conforme reitera $\mathrm{BOBBIO}^{22}$, a Escola Histórica do Direito foi predecessora do positivismo jurídico na Alemanha, através de sua crítica radical do direito natural, conforme o concebia o iluminismo, isto é, como um direito universal e imutável deduzido pela razão ${ }^{23}$.

De outro giro, embora já ressaltada a importância de Savigny ${ }^{24}$ para a Escola Histórica, reitera-se que sua obra representa uma condensação do programa historicista no setor do Direito ${ }^{25}$. Desta forma, cumpre-se registrar o célebre debate entre Thibaut e Savigny, evento mencionado de forma reiterada pela doutrina especializada.

António Thibaut, professor como Savigny em Heidelberg, tinha publicado em 1814 um pequeno livro intitulado: Da necessidade de um direito civil geral para a Alemanha. Assim, nesta obra, sustentava que deviam reunir-se todas as leis vigentes, nos diversos Estados alemães, em um Código único.

Desta tendência racionalista ${ }^{26}$, fez-se Thibaut representante na Alemanha, consignando a favor da codificação argumentos baseados sobretudo na prática, inclusive o significado racional que a unificação do direito privado poderia vir a alcançar nas relações entre os vários Estados alemães ${ }^{27}$.

Por conseguinte, a Thibaut respondeu Savigny através de seu célebre opúsculo $D a$ vocação de nosso tempo para a legislação e a jurisprudência, onde se declarava contrário à Codificação, haja vista que a vida era dinâmica e o código estático. Ademais, considerava as leis (e a fortiori os códigos) como fossilizações do direito, constituindo algo de morto que impede o desenvolvimento ulterior. O Direito, conforme Savigny, viveria na prática e nos costumes, como expressão direta da consciência jurídica popular ${ }^{28}$.

De outra forma, Savigny ainda afirmava que a Alemanha de sua época não estaria em condições culturais favoráveis que possibilitassem uma codificação, 
passando, ao contrário, por um período de decadência, primordialmente no que se diz respeito à ciência jurídica ${ }^{29}$.

O programa da Escola Histórica era, justamente, o de buscar as fontes não estaduais e não legislativas do direito. A sua pré-compreensão da sociedade - subsidiária da filosofia da cultura organicista, evolucionária, do ambiente cultural e político do romantismo alemão - levava-a a conceber a sociedade como um todo orgânico, sujeito a uma evolução histórica semelhante à dos seres vivos, em que no presente se leem os traços do passado e em que este condiciona naturalmente o futuro.

Com efeito, em toda esta evolução, peculiar a cada povo, manifestaria uma lógica própria, um espírito silenciosamente atuante, o "espírito do povo" (Volksgeist), que estaria na origem e, ao mesmo tempo, daria unidade e sentido a todas as manifestações histórico-culturais de uma nação.

Neste sentido, o espírito do povo revelar-se-ia nas produções da sua cultura. Na sua língua, desde logo. Também na poesia popular, nas tradições folclóricas, no direito histórico, nas produções de seus intelectuais, nas suas tradições literárias. Na sua "inocência", o povo exprimir-se-ia numa "multiplicidade" de registros, que, apesar disto, somente as elites culturais conseguiam reduzir a um "sistema científico"30.

Nada obstante, Arnaldo Vasconcelos adverte que, embora a Escola Histórica repouse sua construção jurídica sobre o espírito do povo, nada tem de democrático (no sentido de popular), de acordo com a doutrina da vontade geral (Rousseau). Neste ponto, afirma que "enquanto o costume, estático por definição, tem-se imposto como elemento imobilizador do Direito, tolhendo-lhe o progresso, a vontade geral se atualizaria a todo instante, renovando-se continuadamente" ${ }^{\prime 31}$.

Por outro giro, diversos doutrinadores apresentaram diversas críticas à escola histórica do Direito. Neste sentido, Del Vecchio revela que a doutrina exclui a especulação ideal sobre a justiça, não ocorrendo preocupação com os valores a serem realizados, identificando o dever ser com o real, com o existente ${ }^{32}$.

Da mesma forma, outra crítica que se faz à Escola Histórica consiste na circunstância de que seus principais defensores e adeptos foram grandes admiradores e cultores do Direito Romano, encarando-os como modelo, regularmente válido universalmente ${ }^{33}$.

Assim, esta atitude de culto exacerbado ao Direito Romano evidencia-se como patente contradição da Escola Histórica, na medida em que os historicistas defenderam a tese de que o Direito deveria ser a expressão da vida de um povo, ou seja, o resultado de 
suas experiências, de seu passado, de suas aspirações. Del Vecchio assevera, entretanto, que já houve quem justamente observasse que o Direito Romano teria sido para a Escola Histórica um sucedâneo do Direito Natural, cuja corrente doutrinária foi tão combatida pelos próprios historicistas ${ }^{34}$.

Marques Neto também apresenta as suas considerações à Escola Histórica, inclusive afirmando que, em certa medida, poderia se identificar tanto com as escolas empiristas, quanto com as escolas idealistas. Neste ponto, afirma o Autor que "o posicionamento da Escola Histórica - que, voltando-se para a realidade social do Direito, assume uma atitude empirista; mas, atribuindo a essa realidade a forma abstrata de um espírito coletivo, identifica-se em parte com o idealismo [...]"35.

Nada obstante, Marques Neto também reconhece a escola histórica como a precursora da fundamentação sociológica do Direito, que, posteriormente, seria levado até às últimas consequências pela escola sociológica, senão vejamos:

\footnotetext{
Apesar de suas várias imprecisões - compreensíveis numa escola que é a precursora da fundamentação sociológica do Direito-, a Escola Histórica teve o inegável mérito de abrir caminho para o estudo do fenômeno jurídico no interior do espaço-temporal social que constitui, por assim dizer, sua ambiência ${ }^{36}$.
}

Para Alf Ross, a Escola Histórica do Direito é caracterizada por uma filosofia da história romântico-conservadora, tendo o costume (e não as leis) como a fonte suprema do Direito. Neste ponto, assevera que o direito não seria criado conscientemente de forma racional, sendo produto da consciência jurídica popular ${ }^{37}$.

Igualmente, Arnaldo Vasconcelos afirma que, apesar de a melhor lei ser aquela que provém diretamente do costume, consoante proclamação dos antigos gregos e romanos, equivocado, entretanto, admitir que a sociedade não necessite de leis que ultrapassem as formas consuetudinárias, ainda que por transformações promovidas pela evolução da ciência e da técnica ${ }^{38}$.

Por conseguinte, Vasconcelos também chama a atenção para o papel civilizatório do Direito, assim como da função programática e pedagógica da lei. Neste ponto, afirma que "haverá razões, em repetidas oportunidades, para que sempre se façam leis contra costumes vigentes ${ }^{39}$.

Neste diapasão, com fulcro no Autor António Manuel Hespanha ${ }^{40}$, têm-se algumas ilações acerca das consequências da Escola Histórica sob o ponto de vista da teoria do direito e de sua cientificidade: 
(1) Antilegalismo - A reação da Escola Histórica (debate Thibaut e Savigny) contra o movimento de codificação. Nesta esteira, a lei, inclusive a sistematizada (Código), foi encarada como fator destrutivo do Direito. Primeiro, porque os Códigos introduziriam um elemento conjuntural e decisionista (a decisão legislativa tomada conjunturalmente por um governo ou uma assembleia) num mundo de normas orgânicas, indisponíveis e duráveis (o direito, como emanação do espírito do povo). Segundo, porque congelavam a evolução natural do direito e - como toda a tradição que o é - deveria traduzir-se em uma realidade viva, permanentemente em transformação espontânea;

(2) Valorização da doutrina e dos costumes do Direito - O elemento consuetudinário seria a forma de manifestação espontânea do Direito, enquanto que a doutrina seria uma espécie Professorenrecht (direito dos professores). Neste ponto, a Escola Histórica atribuía aos intelectuais e literatos a revelação organizada e sistemática do espírito do povo;

(3) Revalorização da história do Direito e seu papel dogmático - Que não se apresentaria como algo do passado, separado do presente. De forma contrária, o passado (a tradição) fecundaria o presente, alimentando-o e, por vezes, dogmatizando-o ${ }^{41}$.

(4) Sistematicidade e organicidade da jurisprudência - Decorre do fato de o Direito ser apresentado como um "todo orgânico", através dos desdobramentos do "espírito do povo". Neste ponto, as instituições jurídicas partiriam de uma certa unidade, de todo o Direito nacional de forma sistemática.

Desta forma, a abordagem da Escola Histórica do Direito ora desenvo lvida é com ênfase voltada para a realidade social do Direito (visão da corrente empirista), embora não se descuide de que, eventualmente, possa possuir algum enlace com as correntes idealistas. Nesta esteira empirista, "uma lei será tanto mais eficaz quanto maior for a sua aceitação por parte do meio social a que se dirige" 42 .

Neste contexto, no processo de construção da norma jurídica (Lei) já devem ser considerados os possíveis valores dominantes da sociedade, principalmente os que representem o maior contingente da população (talvez, se trate de um teste de legitimidade a ser proposto).

Decerto, ocorreria então um permanente diálogo dialético entre a norma vigente e o seu respectivo conteúdo social, onde a realidade social seria a mantenedora da última ratio sobre a eficácia ou não da legislação vigente ${ }^{43}$. Tratar-se-ia, portanto, de um diálogo 
sujeito à cláusula rebus sic stantibus, ou seja, as condições iniciais do pacto inicial (dialogado) estariam sempre sujeitas a ulteriores modificações.

Nada obstante a doutrina da Escola Histórica ser apta a fundamentar a norma de Direito positivo, Arnaldo Vasconcelos reitera que tal doutrina perde muito de sua consciência se tomada, em sua totalidade, como filosofia da ciência jurídica. Neste ponto, também destacou a sua importância quanto à historicidade do Direito, numa época de predomínio das abstrações racionalistas 44 .

No próximo tópico desta pesquisa, verificar-se-á o empirismo jurídico (enquanto gênero, do qual a Escola Histórica do Direito é espécie), bem como os seus possíveis obstáculos epistemológicos à cientificidade do Direito. Neste ponto, a análise se dará, precipuamente, de acordo com a teoria do conhecimento proposta por Karl Popper.

\section{O EMPIRISMO JURÍDICO E OS OBSTÁCULOS EPISTEMOLÓGICOS}

Quanto à contribuição da epistemologia (ou teoria do conhecimento) ao estudo do Direito, notável o seu papel na compreensão da ciência jurídica. Ademais, também merece destaque a sua importância no estudo da cognição humana (no campo hermenêutico; na atribuição de sentido aos textos normativos; no plano probatório para detecção dos fatos necessários de incidência de normas) e no âmbito axiológico (quanto aos valores subjacentes às normas $)^{45}$.

Boaventura Santos, asseverando acerca da relação entre epistemologia e ciência, afirma com propriedade que a nossa reflexão epistemológica é muito mais avançada e sofisticada que a nossa prática científica. Neste ponto, afirma que:

\footnotetext{
Duvidamos suficientemente do passado para imaginarmos o futuro, mas vivemos demasiadamente o presente para podermos realizar nele o futuro. Estamos divididos, fragmentados. Sabemo-nos o caminho, mas não exatamente onde estamos na jornada [...] A condição epistemológica da ciência repercute-se na condição existencial dos cientistas. Afinal, se todo o conhecimento é autoconhecimento, também todo o desconhecimento é autodesconhecimento 4
}

Karl Popper, por sua vez, ressalta a importância da epistemologia para as ciências individuais e para a filosofia. Desta maneira, a intranquilidade filosófica e religiosa 
seriam também resultado da intranquilidade epistemológica. Decerto, lapidares são os ensinamentos propostos por Sócrates (ressaltado pelo Autor), notadamente na descoberta (puramente humana e verdadeira) de que não sabemos de nada (figura de linguagem, a busca do conhecimento deve ser uma constante, inclusive para os "sábios")47.

De outro giro, as certezas absolutas das nossas teorias jamais poderão ser racionalmente justificadas. Afirma Popper, contudo, que embora não possamos provar sequer que são prováveis, podemos (e devemos) criticá-las racionalmente (procedimento que em tese se propõe a refutar as teorias piores ou cientificamente descartadas $)^{48}$.

Nesta perspectiva, a falibilidade não seria um limite (barreira intransponível ao conhecimento), mas sim um elemento caracterizador e fundante da nossa própria humanidade (condição antropológica de constituição). Com efeito, arremata Cruz:

\footnotetext{
Não há teoria ou marco infalível. Trabalhar com um marco teórico implica antes de tudo ser crítico do mesmo, sob pena de ortodoxia e dogmatismo. Aquele que é incapaz de ver problemas com seus pressupostos teóricos, de certo, afasta de si a condição primordial da ciência: o espírito crítico! 49
}

Por conseguinte, Karl Popper expõe a necessidade de investigação de dois problemas fundamentais que estariam na base das questões clássicas e modernas acerca da teoria do conhecimento, quais sejam, o problema da indução (Hume) e o da demarcação (Kant). Nesta esteira, as duas questões poderiam ser sintetizadas: (1) Pode- se saber mais do que se sabe? e (2) Quando uma ciência não é uma ciência? ${ }^{50}$

Quanto ao problema da indução, Popper designa "a questão da validade ou da justificação das proposições universais das ciências empíricas. Dito de outro modo: enunciados factuais, que se baseiam na experiência, podem ser válidos universalmente?" 51 Neste ponto, as reflexões do Autor levam em consideração as limitações do homemobservador e que, apesar disto, pretende formular proposições válidas para um número ilimitado de eventos.

No que concerne ao problema da demarcação, ou seja, sobre os limites do conhecimento científico, Popper indaga: "como se pode, em caso de dúvida, decidir se temos diante de nós uma proposição científica ou apenas uma afirmação metafísica?"52

Assim, o Autor propõe reflexões acerca da rejeição ou não da metafísica, bem como a possibilidade de se distingui-la com exatidão da ciência empírica. 
Por outro giro, Machado Segundo assevera que os dados extraídos do "mundo das possibilidades", ou seja, as informações utilizadas pelo homem para julgar o "mundo da realidade" e, consequentemente, realizar as suas escolhas, há a necessidade de se recorrer à metafísica ${ }^{53}$.

Com efeito, fundamentado no falsificacionismo de Popper, diz Machado Segundo que a ciência evolui, de fato, por intermédio de proposições e refutações. Neste ponto, "o conhecimento não se forma da indução pela experiência do real; formula-se a hipótese - metafísica! - e, em seguida, verifica-se se ela, hipótese, corresponde à realidade (falseamento)" ${ }^{\prime 54}$. Tem-se a ilação, portanto, de que não existem nem existirão teorias científicas eternas (imutáveis), ou seja, a sua duração é diretamente proporcional à sua capacidade de resistências aos posteriores testes de refutação.

Do ponto de vista da teoria do conhecimento em geral, entretanto, Popper assevera que, na verdade, o único problema fundamental seria o problema da demarcação. Nesta esteira, afirma o Autor:

O problema da indução surge apenas do problema da demarcação: o método
indutivo desempenha o papel de critério de demarcação: deve ser o elemento
característico da ciência empírica, da ciência factual. [...] Dito de outro modo: uma
teoria do conhecimento correta, que seja capaz de evitar todos os desvios
polêmicos, que não precise se envolver com a situação do problema histórico-
dialético, deveria [...] tratar certamente do problema da demarcação; o problema da
indução e o conceito de indução não precisariam figurar nela. Pois não há indução
no sentido da teoria do conhecimento ${ }^{55}$.

De imediato, antes de refletir acerca dos obstáculos epistemológicos às correntes empiristas, cumpre-se definir o que vem a ser o empirismo jurídico. Segundo Marques Neto, são as correntes que:

Tomam como ponto de partida a suposição de que o conhecimento jurídico resulta de uma captação do objeto pelo sujeito, ou, em outras palavras, de que o conhecimento emana do objeto, seja este tomado como sendo a norma jurídica, seja considerado como o fenômeno jurídico produzido dentro do espaço-tempo social $^{56}$.

Depreende-se, portanto, que o empirismo jurídico se trata de uma orientação jusfilosófica que considera o Direito alicerçado na experiência. Neste ponto, o pensamento jurídico histórico alberga o Direito nascido dos fatos como premissa fundamental sobre a qual se assenta o empirismo jurídico.

Miguel Reale critica tal posicionamento, na medida em que os empiristas pretendem partir dos fatos jurídicos para atingir leis e princípios e, em última análise, 
também pretendem seguir os mesmos fatos para alcançar o conceito universal do Direito. Afirma o Autor, ainda, a possibilidade de partir da experiência para se atingir um conhecimento científico, contudo, os empiristas, quando partem de um fato que declaram jurídico, já estão dando como resolvido aquilo mesmo que se propuseram a resolver ${ }^{57}$.

Retomando os obstáculos epistemológicos às correntes empiristas, lapidares são os ensinamentos de Marques Neto, ao afirmar que o empirismo jurídico constitui obstáculo epistemológico à elaboração científica do Direito. Neste ponto, a corrente empirista privilegiaria em excesso um dos termos da relação cognitiva (o objeto), afastando a ideia dialética de que é no processo relacional entre sujeito e objeto que ocorre a construção do conhecimento científico ${ }^{58}$.

Com efeito, Marques Neto também vai ao encontro de Karl Popper. Explico. De acordo com o que se abordou acima sobre o verdadeiro problema fundamental da epistemologia, qual seja, o problema da demarcação, a dificuldade consistiria em distinguir, inequivocamente, a metafísica da ciência empírica.

Nesta esteira, Marques Neto afirma que "tanto quanto o idealismo, o empirismo jurídico se caracteriza por adotar uma atitude metafísica diante do processo cognitivo"59. Desta forma, corroborando com a doutrina de Popper, comunga-se do entendimento de que o empirismo jurídico (aqui abordado através da Escola Histórica do Direito) constitui-se em obstáculo epistemológico à cientificidade do direito.

Outrossim, o próprio Karl Popper afirmou conhecer todos os argumentos epistemológicos - predominantemente subjetivistas - a favor das diversas alternativas filosóficas (ismos filosóficos - positivismo, idealismo, fenomenismo, etc.). No entanto, considera o Autor todos equivocados (com exceção do realismo) ${ }^{60}$, na medida em que a maioria deles resulta da busca da certeza ou de alicerces sólidos para construção de teorias.

Desta forma, segundo Popper, isto se trataria de "erro típico de filósofo"61, ou seja, decorrente de uma teoria errônea do conhecimento calcificada no senso comum, não imune a críticas. Decerto, a perene possibilidade de falseamento futuro das teorias deve se mostrar característica inerente ao conhecimento científico.

\section{CONSIDERAÇÕES FINAIS}


Apesar dos embates travados entre jusnaturalistas e historicistas, admite-se a importância da teoria da Escola Histórica, principalmente pela consagração dos princípios da historicidade e da relatividade do direito. Vislumbra-se, ainda, a possível harmonia entre os imperativos da natureza humana universalista e racionalista em conformidade com a realidade social como produto histórico e espontâneo de cada povo.

Com apoio da epistemologia, verifica-se, inequivocamente, que não existem teorias científicas eternas, isto é, a sua respectiva duração é diretamente proporcional à sua capacidade de resistências aos posteriores testes de refutação. Extrai-se, também, a consagração do axioma da relatividade (pelo menos na concepção de mundo que a natureza humana possui a capacidade de cognição - espaço, tempo, etc.).

Assim, com base na doutrina de Karl Popper, a maioria das escolas teóricas incorrem em equívocos quando buscam na certeza absoluta as bases para construção de suas teorias. Nesta medida equivocada, também se refere ao conhecimento norteado no senso comum e em dogmas históricos do passado, haja vista a permanente possibilidade de falseamento futuro das eventuais hipóteses formuladas.

Quanto ao empirismo jurídico, tem-se a ilação de que constitui obstáculo epistemológico à elaboração científica do Direito. Neste ponto, há uma inequívoca tendência em privilegiar um dos termos da relação cognitiva, qual seja o objeto, afastando a ideia dialética de que é no processo relacional - sujeito e objeto - que ocorre a construção do conhecimento científico

Com efeito, verifica-se que a falibilidade humana (que lhe é inerente) impõe ao homem-observador limitações que, por si, já o impediriam, em tese, da pretensão de formular possíveis proposições baseadas na experiência supostamente válidas para um número ilimitado de eventos.

\section{REFERÊNCIAS BIBLIOGRÁFICAS}

ATLAN, Henri. Será que a ciência cria valores? O bom, o verdadeiro e o poeta. In: PESSIS-PASTERNAK, Guitta. A ciência: Deus ou Diabo? Tradução de Edgard de Assis Carvalho e Mariza Perassi Bosco. São Paulo: Unesp, 2001, p.183-185.

BITTAR, Eduardo Carlos Bianca; ALMEIDA, Guilherme Assis de. Curso de filosofia do direito. São Paulo: Atlas, 2010. 
BOBBIO, Norberto. O Positivismo Jurídico: lições de filosofia do direito. Tradução de Mário Pugliesi. São Paulo: Ícone, 1995.

BONAVIDES, Paulo. Do Estado Liberal ao Estado Social. 9ed. São Paulo: Malheiros, 2009.

CRUZ, Álvaro Ricardo de Souza. O discurso científico na modernidade: o conceito de paradigma é aplicável ao direito? Rio de Janeiro: Lumen Juris, 2009.

DEL VECCHIO, Giorgio. Lições de Filosofia do Direito. 5ed. Tradução de Antônio José Brandão. Coimbra, 1979.

HESPANHA, António Manuel. Cultura jurídica europeia: síntese de um milênio. 3ed., Mira-Sintra: Publicações Europa-América, 2003.

MARQUES NETO, Agostinho Ramalho. A ciência do direito: conceito, objeto, método. 2ed. Rio de Janeiro: Renovar, 2001.

NADER, Paulo. Filosofia do Direito. 19ed. Rio de Janeiro: Forense, 2010.

POPPER, Karl. A lógica das ciências sociais. Tradução de Estêvão de Rezende Martins. 3ed. Rio de Janeiro: Tempo Brasileiro, 2004, p. 33.

A vida é aprendizagem. Epistemologia evolutiva e sociedade aberta. Tradução de Paula Taipas. Lisboa: Edições 70, 2001.

- Os dois problemas fundamentais da teoria do conhecimento. Tradução Antônio Lanni Segatto. 1ed. São Paulo: Editora Unesp. 2013.

. Realismo. In: MILLER, David (Org.). Popper: textos escolhidos. Tradução de Vera Ribeiro. Rio de Janeiro: Contraponto, 2010, p.220-221.

PRIGOGINE, Ilya. O fim das certezas: tempo, caos e as leis da natureza. São Paulo: Unesp, 1996. Prólogo.

REALE, Miguel. Filosofia do Direito. 19ed. São Paulo: Saraiva, 1999.

ROSS, Alf Niels Christian. Direito e justiça. Tradução de Edson Bini. Bauru: Edipro, 2000.

SANTOS, Boaventura de Sousa. Um discurso sobre as ciências. 7ed. Porto: Edições afrontamento, 1995.

SEGUNDO, Hugo de Brito Machado. Epistemologia falibilista e teoria do direito. RIDB. Ano 3 (2014), no 1, 197-260 / http://www.idb-fdul.com/ ISSN: 2182-7567.

Fundamentos do direito. São Paulo: Atlas, 2010.

VASCONCELOS, Arnaldo. Teoria da norma jurídica. 3ed. São Paulo: Malheiros, 1993. 
${ }^{1}$ BITTAR, Eduardo Carlos Bianca; ALMEIDA, Guilherme Assis de. Curso de filosofia do direito. São Paulo: Atlas, 2010, p. 279.

${ }^{2}$ MACHADO SEGUNDO, Hugo de Brito. Fundamentos do direito. São Paulo: Atlas, 2010, p. 26.

${ }^{3}$ VASCONCELOS, Arnaldo. Teoria da norma jurídica. 3ed. São Paulo: Malheiros, 1993, p.101.

${ }^{4}$ Ao se debruçar sobre os pressupostos mínimos para a construção de um ordenamento jurídico justo, afirma Machado Segundo que o ponto nodal distintivo do animal-homem para os demais animais reside no fato de que aquele é capaz de diferenciar o mundo-real do mundo-possível. Nesta medida, giraria o valor humano liberdade, além de inúmeras contradições que permeariam a finita natureza humana, porém recheada de infinitas possibilidades. Fala-se, portanto, em compartilhamento de liberdades. Desta forma, a absoluta liberdade do indivíduo de um determinado grupo social (ou seja, o uso exacerbado ou ilimitado da liberdade) também redundaria (por via de consequência) em uma sujeição também absoluta ou irrestrita dos demais membros daquele grupo considerado (destaque nosso). MACHADO SEGUNDO, Hugo de Brito. Fundamentos do direito. São Paulo: Atlas, 2010, p. 87-125.

${ }^{5}$ NADER, Paulo. Filosofia do Direito. 19ed. Rio de Janeiro: Forense, 2010, p.188.

6 DEL VECCHIO, Giorgio. Lições de Filosofia do Direito. 5ed. Tradução de Antônio José Brandão. Coimbra, 1979. p.148.

${ }^{7}$ Ibidem, passim.

8 "Esta escola tem, pois, qualquer coisa de retrógrado e anacrônico, o que se revela, sobretudo, na hostilidade acérrima às ideias liberais, embora estas representassem uma aquisição e um progresso irrepudiável para a consciência dos novos tempos”. DEL VECCHIO, Giorgio. Ob. Cit., p.150.

${ }^{9}$ Ibidem, p.148-150.

${ }^{10}$ NADER, Paulo. Ob. Cit., p.188.

${ }^{11}$ DEL VECCHIO, Giorgio. Ob. Cit., p.157-158. Conferir também: NADER, Paulo. Ob. Cit., p.188.

12 BOBBIO, Norberto. O Positivismo Jurídico: Lições de Filosofia do Direito. Tradução de Mário

Pugliesi. São Paulo: Ícone, 1995, p. 47-51.

13 Depreende-se que o tempo seria a dimensão fundamental de nossa existência e do conhecimento (principalmente da Física galileana, ponto de partida da ciência ocidental). Com base na teoria de Einstein, afirma-se que o tempo seria então uma ilusão, não autorizando aprioristicamente nenhuma distinção entre o passado e o futuro. Por outro giro, tem-se o "paradoxo do tempo", qual seja, a transposição para a Física do "dilema do determinismo": Como poderia a flecha do tempo emergir de um mundo a que a física atribui uma simetria temporal? A princípio, a explicação originava-se da fenomenologia, isto é, pelo fato de os observadores (humanos, falhos e limitados) seriam então os responsáveis pela diferença entre passado e futuro. Com efeito, a evolução da ciência ilide a tese de que a flecha do tempo seria apenas fenomenológica, e, dentre outras perspectivas possíveis, 'assistimos ao surgimento de uma ciência que não mais se limita a situações simplificadas, idealizadas, mas nos põe diante da complexidade do mundo real, uma ciência que permite que se viva a criatividade humana como a expressão singular de um traço fundamental comum a todos os níveis da natureza'13. PRIGOGINE, Ilya. O fim das certezas: tempo, caos e as leis da natureza. São Paulo: Unesp, 1996. Prólogo, p.14.

${ }^{14}$ BOBBIO, Norberto. O Positivismo Jurídico: Lições de Filosofia do Direito. Tradução de Márcio

Pugliesi. São Paulo: Ícone, 1995, p.45-46.

${ }^{15}$ BOBBIO, Norberto. Ob. Cit., p.47-48.

16 Ibidem, p.48.

${ }^{17}$ NADER, Paulo. Ob. Cit., passim.

18 Ibidem, p. 188.

${ }^{19}$ Ibidem, p. 187.

20 "A tarefa de todos os precursores da Escola Histórica foi combater os princípios absolutos, o racionalismo inovador, revolucionário, que supunha poder reformar de súbito as sociedades, transplantando instituições de uma nação para outra, ou realizando na vida jurídica as meras criações abstratas da razão, apoiada quando muito na observação subjetiva”. Cf. LESSA, Pedro. Filosofia do Direito. 2ed. Rio de Janeiro: Livraria Francisco Alves, 1916, p.379, Apud NADER, Paulo. Ob. Cit., p.188.

21 BOBBIO, Norberto. O Positivismo Jurídico: Lições de Filosofia do Direito. Tradução de Márcio Pugliesi. São Paulo: Ícone, 1995, p.45

22 Ibidem, passim.

23 “Ao Direito Natural a escola histórica contrapõe o direito consuetudinário, considerado como a forma genuína do direito, enquanto expressão imediata da realidade histórico-social e do Volksgeist. A atitude antijusnaturalista é congênita a todo pensamento jurídico que sustentou em primeiro plano o costume".

BOBBIO, Norberto. Ob. Cit., p.53-54.

Revista de Pesquisa e Educação Jurídica | e-ISSN: 2525-9636 | Minas Gerais | v. 1 | n. 2 | p. 01 - 22 | Jul/Dez. 2015. 
${ }^{24} \mathrm{O}$ professor Paulo Bonavides assinala que "O princípio fundamental de que a Sociedade se rege por leis orgânicas cobrou no Direito sua primeira justificação depois do célebre manifesto de Savigny a favor da escola histórica". BONAVIDES, Paulo. Do Estado Liberal ao Estado Social. 9ed. São Paulo: Malheiros, 2009. p.81.

${ }^{25}$ NADER, Paulo. Ob. Cit., p.189.

26 "A tendência para a unificação legislativa era, aliás, consequência lógica da orientação racionalista. Com efeito, não foi por acaso que os homens da Revolução Francesa, depois de proclamados os direitos do homem e do cidadão (1789), começaram a preocupar-se com a elaboração das normas do direito privado, para as recolherem na unidade sistemática daquele Código, que, aprovado em 1804, ainda hoje vigora em França". Cf. DEL VECCHIO, Giorgio. Ob. Cit., p.159.

${ }^{27}$ Ibidem.

28 "A consciência jurídica popular é um conceito típico que a Escola histórica do direito tirou do historicismo filosófico de Schelling e Hegel, a ponto de se poder dizer que ela não é senão uma aplicação particular das doutrinas daqueles filósofos no campo do direito". Ibidem.

${ }^{29}$ BOBBIO, Norberto. Ob. Cit., p.61.

30 Henri Atlan tenta demonstra a existência de várias lógicas para compreensão da realidade, ou seja, 'atribuir o raio do trovão à cólera de Júpiter não é menos racional do que explicá-lo como descarga elétrica' Neste ponto, parece o Autor refutar a tese de que a ciência não criaria valores, haja vista que inexiste ciência totalmente neutra, assim como método de pesquisa a ciência institui internamente aquilo que é cientificamente válido ou não. Defende ainda a necessidade de encontro do "meio termo" entre a tendência a divinizar o valor da ciência (somente a verdade científica seria admissível) ou a propensão em diabolizá-la (a verdade científica relativizada ou refutada de plano). Por outro giro, o Autor reconhece a indispensabilidade do conhecimento científico, porquanto apresenta as contradições inerentes ao erro e ao engano, isto é, aquilo que fosse cientificamente falso não poderia, em tese, servir como descrição da realidade. Neste ponto, as fraudes e os preconceitos (alguns alicerçados pelo conhecimento dogmático ou não-científico) seriam desmascarados, ou seja, a razão poderia servir para explicação do irracional. Com efeito, o pensamento do Autor se revela com propriedade na afirmação: 'o que é cientificamente falso não pode descrever a realidade, mas a recíproca positiva também não funciona: o que é cientificamente verdadeiro não esgota a realidade' (destaques nossos). ATLAN, Henri. Será que a ciência cria valores? O bom, o verdadeiro e o poeta. In: PESSIS-PASTERNAK, Guitta. A ciência: Deus ou Diabo? Tradução de Edgard de Assis Carvalho e Mariza Perassi Bosco. São Paulo: Unesp, 2001, p.183-185.

${ }^{31}$ VASCONCELOS, Arnaldo. Teoria da norma jurídica. 3ed. São Paulo: Malheiros, 1993, p.111.

32 DEL VECCHIO, Giorgio. Ob. Cit., passim.

${ }^{33}$ NADER, Paulo. Ob. Cit., p. 190.

${ }^{34}$ DEL VECCHIO, Giorgio. Ob. Cit., passim.

${ }^{35}$ MARQUES NETO, Agostinho Ramalho. A ciência do direito: conceito, objeto, método. 2ed. Rio de Janeiro: Renovar, 2001, p.155.

${ }^{36}$ Ibidem, p.155-156.

${ }^{37}$ ROSS, Alf Niels Christian. Direito e justiça. Tradução de Edson Bini, Bauru: Edipro, 2000, p.291.

${ }^{38}$ VASCONCELOS, Arnaldo. Teoria da norma jurídica. 3ed. São Paulo: Malheiros, 1993, p.111.

${ }^{39}$ VASCONCELOS, Arnaldo. Teoria da norma jurídica. 3ed. São Paulo: Malheiros, 1993, p.111.

${ }^{40}$ HESPANHA, António Manuel. Cultura jurídica europeia: síntese de um milênio. 3ed., Mira-Sintra: Publicações Europa-América, 2003, p.272-274.

41 Conforme Karl Popper, 'todo o conhecimento pré-científico, animal ou humano, é dogmático; e a ciência começa com a invenção do método crítico não dogmático'. Neste ponto, tem-se a ilação de que o dogma e o conhecimento científico são inconciliáveis, na perspectiva da abordagem crítica proposta pelo Autor (formulações objetivas, públicas e linguísticas de suas teorias). Por outro giro, a prin cipal tese defendida por Popper se trata da distinção entre a abordagem científica e a abordagem pré-científica, qual seja, o método de tentativa de falibilismo. Nesta medida, o método científico propiciaria a escolha das melhores teorias que, por conseguinte, suportariam a rigorosos testes e resistiriam a severas críticas. Com efeito, tal distinção se fundamentaria na atitude consciente e crítica da abordagem científica em relação às tentativas de solução do problema proposto: considera uma parte ativa nas tentativas de eliminação, isto é, nas tentativas de criticar e falibilizar. De maneira diferente, a atitude dogmática (via de regra, imune às críticas e às tentativas falibilistas) se trataria essencialmente de característica precípua da abordagem pré-científica (destaques nossos). POPPER, Karl. A vida é aprendizagem. Epistemologia evolutiva e sociedade aberta. Tradução de Paula Taipas. Lisboa: Edições 70, 2001, p. 17 40.

42 MARQUES NETO, Agostinho Ramalho. A ciência do Direito: conceito, objeto, método. 2.ed. Rio de Janeiro: Renovar, 2001, p. 201. 
${ }^{43}$ Ibidem.

44 VASCONCELOS, Arnaldo. Teoria da norma jurídica. 3ed. São Paulo: Malheiros, 1993, p.111.

45 SEGUNDO, Hugo de Brito Machado. Epistemologia falibilista e teoria do direito. RIDB. Ano 3 (2014), no 1, 197-260 / http://www.idb-fdul.com/ ISSN: 2182-7567.

46 SANTOS, Boaventura de Sousa. Um discurso sobre as ciências. 7ed. Porto: Edições afrontamento, 1995, p.36; p.58.

47 POPPER, Karl. A lógica das ciências sociais. Tradução de Estêvão de Rezende Martins. 3ed. Rio de Janeiro: Tempo Brasileiro, 2004, p. 33.

${ }^{48}$ Ibidem, 13-34.

49 CRUZ, Álvaro Ricardo de Souza. O discurso científico na modernidade: o conceito de paradigma é aplicável ao direito? Rio de Janeiro: Lúmen Juris, 2009, p. 223.

50 POPPER, Karl Raimund. Os dois problemas fundamentais da teoria do conhecimento. Tradução Antônio Lanni Segatto. 1ed. São Paulo: Editora Unesp. 2013.

${ }^{51}$ Ibidem, p.3.

52 Ibidem, p.4.

${ }^{53}$ Conforme o Autor, o emprego do vocábulo "metafísica" não se refere à religião (ou a um mundo ideal por si e em si sem a ingerência do homem). Afirma: "trata-se apenas de algo que não tem existência física ou concreta, e que não se confunde com o que é apreendido pelos sentidos, embora através dos sentidos se possa ter acesso aos sinais que servem de transporte a essa realidade". MACHADO SEGUNDO, Hugo de Brito. Fundamentos do direito. São Paulo: Atlas, 2010, p.97.

54 Ibidem, p.96.

55 POPPER, Karl Raimund. Os dois problemas fundamentais da teoria do conhecimento. Tradução Antônio Lanni Segatto. 1ed. São Paulo: Editora Unesp. 2013, p.386-387.

56 MARQUES NETO, Agostinho Ramalho. A ciência do direito: conceito, objeto, método. 2ed. Rio de Janeiro: Renovar, 2001, p.150.

${ }^{57}$ REALE, Miguel. Filosofia do Direito. 19ed. São Paulo: Saraiva, 1999, p.321.

58 MARQUES NETO, Agostinho Ramalho. A ciência do direito: conceito, objeto, método. 2ed. Rio de Janeiro: Renovar, 2001, p.150.

${ }^{59}$ Ibidem.

60 Adiante, fundamenta sua opção epistemológica pelo realismo em dois grandes homens (segundo o Autor), quais sejam: Albert Einstein e Winston Churchill. O primeiro - cientista renomado - afirmara: 'não vejo nenhum perigo metafísico em aceitarmos coisas - isto é, os objetos da física [...] juntamente com as estruturas espaço temporais que lhe são pertinentes'. O segundo - Churchill - apesar de desconhecido como epistemólogo e de não provar o realismo - tratou de apresentar a principal refutação contra a epistemologia subjetivista, segundo o Autor. Neste ponto, se utilizando de exemplo com o Sol, Churchill afirmara que a realidade do astro se comprovava pelos sentidos físicos; assim como pela astronomia, pela matemática e pela razão pura, independentemente da obtenção de dados pela evidência de sentidos (estes dados poderiam ter sido apreendidos por máquinas calculadoras automáticas acionadas pela luz que incide sobre elas, sem ingerência dos sentidos humanos em nenhuma etapa) (destaque nosso). POPPER, Karl. Realismo. In: MILlER, David (Org.). Popper: textos escolhidos. Tradução de Vera Ribeiro. Rio de Janeiro: Contraponto, 2010, p.220-221.

61 POPPER, Karl. Realismo. In: MILLER, David (Org.). Popper: textos escolhidos. Tradução de Vera Ribeiro. Rio de Janeiro: Contraponto, 2010, p.220. 